Article

\title{
L-Glutamine and Whole Protein Restore First-Phase Insulin Response and Increase Glucagon-Like Peptide-1 in Type 2 Diabetes Patients
}

\section{Dorit Samocha-Bonet ${ }^{1,2, *}$, Don J. Chisholm ${ }^{1}$, Jens J. Holst ${ }^{3}$ and Jerry R. Greenfield ${ }^{1,2,4}$}

1 Diabetes \& Metabolism Division, Garvan Institute of Medical Research, 384 Victoria Street, Darlinghurst 2010, Sydney, NSW, Australia; E-Mails: d.chisholm@garvan.org.au (D.J.C.); j.greenfield@garvan.org.au (J.R.G.)

2 Faculty of Medicine, UNSW Australia, High Street, Kensington 2052, Sydney, NSW, Australia

3 NNF Center for Basic Metabolic Research, Department of Biomedical Sciences, University of Copenhagen, Panum Institute, Nørregade 10, DK-1165 Copenhagen, Denmark; E-Mail: jjholst@sund.ku.dk

4 Department of Endocrinology and Diabetes Center, St. Vincent's Hospital, 390 Victoria Street, Darlinghurst 2010, Sydney, NSW, Australia

* Author to whom correspondence should be addressed; E-Mail: d.samochabonet@garvan.org.au; Tel.: +61-2-92958309; Fax: +61-2-92958201.

Received: 21 January 2015 / Accepted: 12 March 2015/ Published: 24 March 2015

Abstract: L-glutamine triggers glucagon-like peptide-1 (GLP-1) release from L cells in vitro and when ingested pre-meal, decreases postprandial glycaemia and increases circulating insulin and GLP-1 in type 2 diabetes (T2D) patients. We aimed to evaluate the effect of oral L-glutamine, compared with whole protein low in glutamine, on insulin response in well-controlled T2D patients. In a randomized study with a crossover design, T2D patients $(n=10,6$ men) aged $65.1 \pm 5.8$, with glycosylated hemoglobin $(\mathrm{HbA1c}) 6.6 \% \pm 0.7 \%$ (48 $\pm 8 \mathrm{mmol} / \mathrm{mol})$, received oral L-glutamine $(25 \mathrm{~g})$, protein $(25 \mathrm{~g})$ or water, followed by an intravenous glucose bolus $(0.3 \mathrm{~g} / \mathrm{kg})$ and hyperglycemic glucose clamp for $2 \mathrm{~h}$. Blood was frequently collected for analyses of glucose, serum insulin and plasma total and active GLP-1 and area under the curve of glucose, insulin, total and active GLP-1 excursions calculated. Treatments were tested 1-2 weeks apart. Both L-glutamine and protein increased first-phase insulin response $(p \leq 0.02)$. Protein $(p=0.05)$, but not L-glutamine $(p=0.2)$, increased second-phase insulin response. Total GLP-1 was increased by both L-glutamine and protein $(p \leq 0.02)$. We conclude that oral L-glutamine and whole protein are similarly 
effective in restoring first-phase insulin response in T2D patients. Larger studies are required to further investigate the utility of similar approaches in improving insulin response in diabetes.

Keywords: glutamine; insulin response; hyperglycemic glucose clamp; type 2 diabetes

\section{Introduction}

Glucagon like peptide-1 (GLP-1) secreted from gastrointestinal L cells has a major role in mediating physiological insulin release following a meal $[1,2]$. Numerous clinical studies suggest that well-controlled type 2 diabetes patients exhibit an intact GLP-1 secretion pattern, comparable to that of healthy individuals [3]. Furthermore, insulin release from the beta cell in response to endogenous GLP-1 is preserved in well-controlled type 2 diabetes [4]. Therefore, there has been much recent interest in developing methods by which GLP-1 action can be enhanced in diabetes. Glutamine is the most efficacious amino acid to trigger GLP-1 release from the L cells model GLUTag cells [5] and native murine L cells ex vivo [6]. In type 2 diabetes patients, ingestion of L-glutamine prior to a meal increases circulating GLP-1 [7-9], delays gastric emptying [8], increases circulating insulin and lowers postprandial glycaemia [9]. While glutamine is the most efficacious amino acid to induce GLP-1 release from L cells, most amino acids exhibit insulinotropic effects [10].

The aim of the present study was to compare the effects of oral glutamine with whole protein low in glutamine on: (i) first- and second- phase insulin response using the gold standard hyperglycemic glucose clamp; and (ii) total and active GLP-1 in well-controlled type 2 diabetes patients. We hypothesized that glutamine would be more efficacious than whole protein in restoring insulin response due to greater increases in GLP-1.

\section{Experimental Section}

\subsection{Participants}

Type 2 diabetes patients were recruited through advertisements at the St Vincent's Hospital precinct, Sydney and in local newspapers. Inclusion criteria were age 40-70 years, diabetes duration of 5 years or less, treatment with diet or metformin in a stable dose ( $\leq 2000 \mathrm{mg} /$ day, for at least 3 months), glycosylated hemoglobin $\left(\mathrm{HbA}_{1 \mathrm{c}}\right) 6.5 \%-9 \%(48-75 \mathrm{mmol} / \mathrm{mol})$, body mass index (BMI) $40 \mathrm{~kg} / \mathrm{m}^{2}$ or less and stable body weight in the preceding 6 months $( \pm 2 \mathrm{~kg})$. Exclusion criteria were treatment with oral hypoglycemic agents other than metformin, ethanol intake $>20$ or $40 \mathrm{~g}$ /day for women and men, respectively, liver or kidney disease or abnormal full blood count, renal or liver function tests, use of weight loss medications, previous bowel surgery or documented malabsorption. The study was approved by the Human Research and Ethics Committee at St Vincent's Hospital and participants gave written informed consent prior to commencement of the study. The study was registered at ClinicalTrials.gov (NCT-00673894). 


\subsection{Study Design}

The effect of glutamine compared with protein and water were evaluated in a randomized crossover study. Participants attended the Clinical Research Facility after an overnight fast on three separate occasions 1-2 weeks apart in a random order. The effects of: (1) $25 \mathrm{~g}$ L-glutamine (Cambridge Commodities, Cambridge, UK) supplemented with $16 \mathrm{~g}$ Philadelphia cheese (26 g protein, $5 \mathrm{~g}$ fat, $152 \mathrm{kcal}$; Gln treatment); or (2) $200 \mathrm{~g}$ low fat cottage cheese (25 g protein, $2 \mathrm{~g}$ Gln [11], $5 \mathrm{~g}$ fat and $182 \mathrm{kcal}$; Protein treatment); or (3) water on the study endpoints were investigated.

\subsection{Study Procedures}

Two intravenous cannulas were inserted for glucose infusion and blood withdrawal. Glutamine was mixed in cold water $(250 \mathrm{~mL})$ and the same water volume was given in all studies. Blood was drawn fasting twice $10 \mathrm{~min}$ apart (averaged concentrations are presented for all endpoints), then treatment ingested within $8 \mathrm{~min}$ and blood collected at $\mathrm{t}=15$ and $30 \mathrm{~min}$. At $\mathrm{t}=30$, glucose $(0.3 \mathrm{~g} / \mathrm{kg}$, maximum $25 \mathrm{~g}$; 25\% glucose, Baxter Healthcare, Old Toongabbie, NSW, Australia) was injected intravenously over $1 \mathrm{~min}$ followed by frequent blood sampling for $10 \mathrm{~min}(\mathrm{t}=30-40)$. Hyperglycemia was then maintained (target $10.8 \mathrm{mmol} / \mathrm{L}$ ) for additional $110 \mathrm{~min}(\mathrm{t}=40-150 \mathrm{~min}$ ) by adjusting glucose infusion rate (GIR) according to $10 \mathrm{~min}$ blood glucose readings.

\subsection{Laboratory Analyses}

Blood glucose (Yellow Springs Instrument Company; Life Sciences) and serum insulin (radioimmunoassay; Millipore, St Charles, IL, USA) were measured at $t=0,15$ and 30 min post $\mathrm{Gln} /$ protein/water treatment, at $\mathrm{t}=1,2,3,4,5,6,8$ and $10 \mathrm{~min}$ post intravenous glucose bolus $(\mathrm{t}=30-40 \mathrm{~min})$ and at $\mathrm{t}=60,90,120,130,140$ and $150 \mathrm{~min}$ during the hyperglycemic glucose clamp. Blood samples for total and active GLP-1 were collected into EDTA-coated tubes, with dipeptidyl peptidase (DPP) 4 inhibitor and trasylol in the active GLP-1 testing tube, and immediately centrifuged for $7 \mathrm{~min}$ at $4100 \mathrm{~g}$, snap frozen, and stored at $-80{ }^{\circ} \mathrm{C}$ until analysis. Total GLP-1 was measured by radioimmunoassay after extraction of plasma with 70\% ethanol. Carboxy-terminal GLP-1 immunoreactivity was determined using antiserum 89390. Active GLP-1 was analyzed using an ELISA, as previously described [12]. Total and active GLP-1 plasma concentrations were measured at $t=0,15$ and 30 min post $\mathrm{Gln} /$ protein/water treatment and at $\mathrm{t}=60,90,140$ and $150 \mathrm{~min}$ during the hyperglycemic glucose clamp.

\subsection{Statistical Analysis}

Area under the curves (AUCs) of glucose, insulin and total and active GLP-1 excursions were calculated (baseline concentrations of these endpoints were not significantly different between treatments, $p>0.1$ ). AUCs were calculated for the $30 \mathrm{~min}$ after ingestion of $\mathrm{Gln} /$ protein/water $\left(\mathrm{AUC}_{0-30 \mathrm{~min}}\right), 10 \mathrm{~min}$ post IV glucose injection ( $\mathrm{t}=30-40$; AUC IVGTT; first-phase insulin response) and for the hyperglycemic glucose clamp ( $\mathrm{t}=40-150 \mathrm{~min}$; AUC Clamp; second-phase insulin response). Data are presented as means $\pm \mathrm{SD}$, unless stated otherwise. Insulin data were $\log _{10}$-transformed prior to statistical analysis. One-way ANOVA with Tukey posthoc comparisons was used to test for differences in AUCs of endpoints 
between L-glutamine, whole protein and water. Data were analyzed using SPSS version 21 (IBM Corp., Armonk, NY, USA).

\section{Results}

Well-controlled type 2 diabetes patients ( $n=10,6$ men, 4 women, all postmenopausal) participated in the study. Participants were $65.1 \pm 5.8$ years old with diabetes duration of $3.5 \pm 1.5$ years, BMI $27.1 \pm 2.4 \mathrm{~kg} / \mathrm{m}^{2}$ and $\mathrm{HbAlc} 6.6 \% \pm 0.7 \%(48 \pm 8 \mathrm{mmol} / \mathrm{mol})$.

\subsection{Blood Glucose Response}

The treatments were well tolerated. Baseline blood glucose was $6.6 \pm 1.3 \mathrm{mmol} / \mathrm{L}$, without significant differences between treatments $(p=0.7)$. Blood glucose peaked 2 min after the IV glucose bolus $(17.3 \pm 2.7 \mathrm{mmol} / \mathrm{L})$, without significant differences between treatments $(p=0.2)$. Blood glucose was clamped at an average of $10.8 \pm 0.4 \mathrm{mmol} / \mathrm{L}$ during clamp steady state $(\mathrm{t}=120-150 \mathrm{~min})$, without a significant difference between treatments $(p=0.3)$. Glucose AUCs were not significantly different between the treatments ( $p \geq 0.5$, Figure 1A,B). Glucose infusion rate (GIR) and GIR normalized to body weight necessary to maintain hyperglycemia were not significantly different between treatments $(p>0.25)$, consistent with similar acute effects of the treatments on insulin sensitivity.

\subsection{Serum Insulin Response}

Insulin $\mathrm{AUC}_{0-30 \min }$ was not significantly different between treatments ( $p=0.1$; Figure $\left.1 \mathrm{C}, \mathrm{D}\right)$. First-phase insulin response (Insulin AUC IVGTT) was blunted after water and augmented by both Gln $(p=0.02)$ and protein $(p=0.01$; Figure 1C inset and D). Second-phase insulin response (Insulin AUCClamp) was significantly augmented by protein $(p=0.05)$, but not $\operatorname{Gln}(p=0.2)$ compared with water (Figure 1C,D).
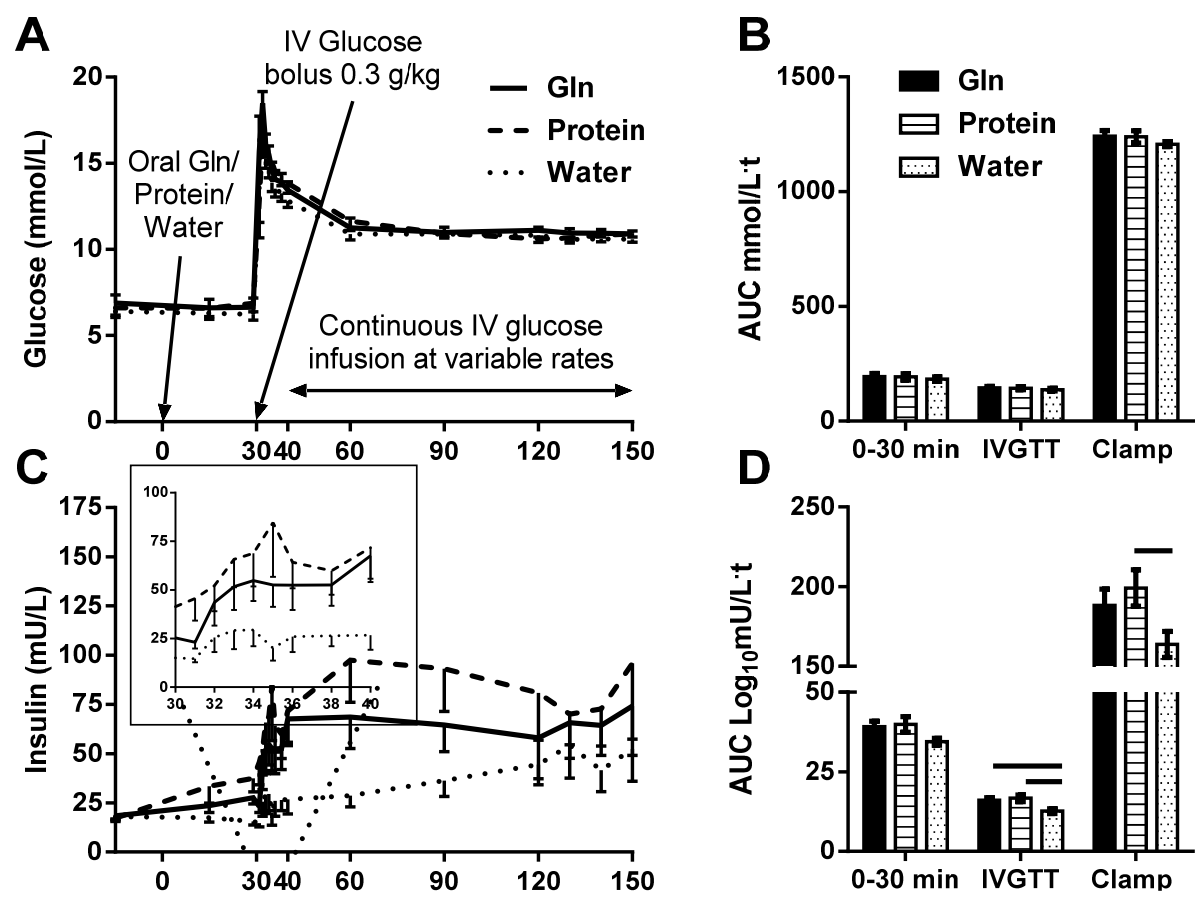

Figure 1. Cont. 

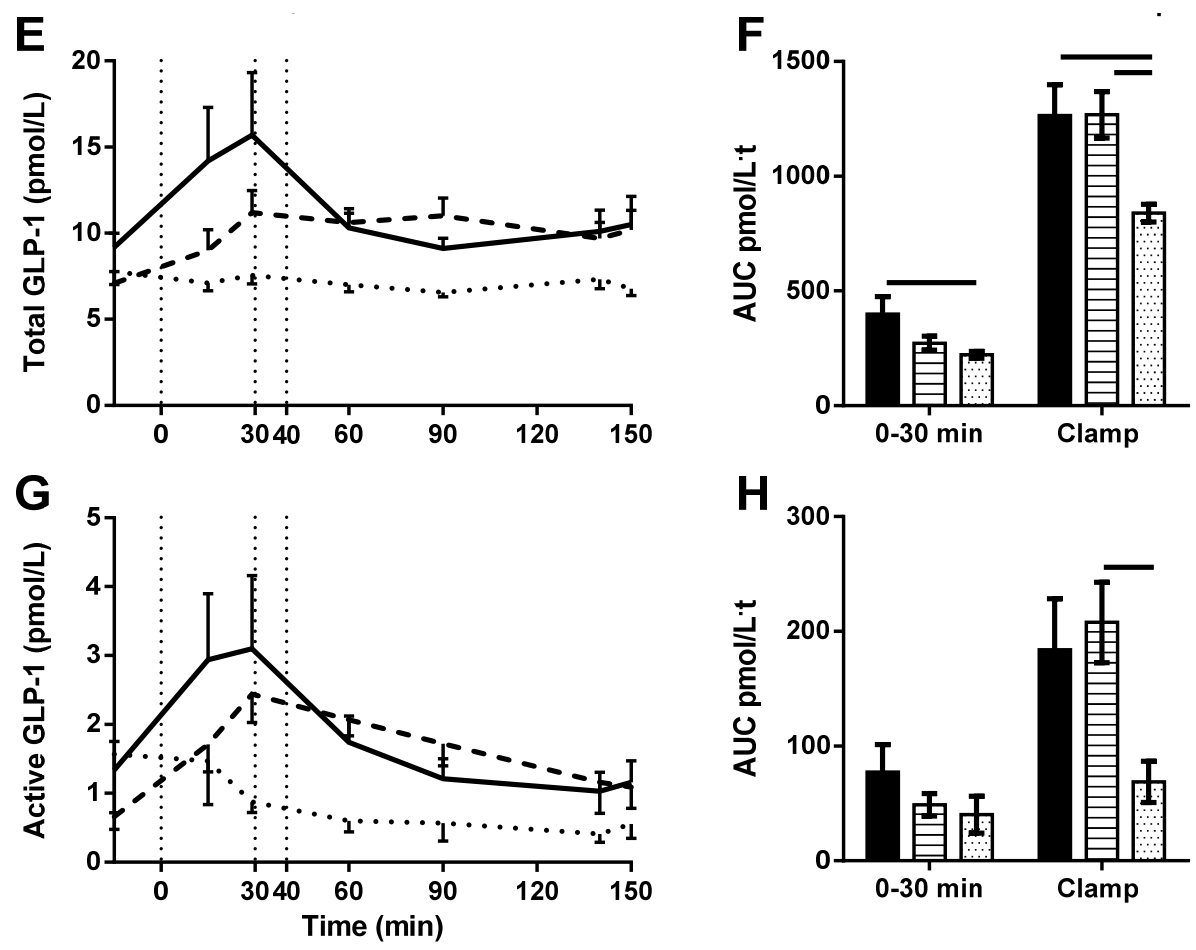

Figure 1. The effect of L-glutamine $(\mathrm{Gln})$, protein or water on blood glucose $(\mathbf{A}$ and $\mathbf{B})$, serum insulin (C; first-phase insulin response, inset, and $\mathbf{D})$ and plasma total $(\mathbf{E}$ and $\mathbf{F})$ and active ( $\mathbf{G}$ and $\mathbf{H}$ ) GLP-1 excursions and area under the curve (AUC), respectively in response to intravenous glucose bolus and hyperglycemic glucose clamp. AUC of the response of glucose, insulin and total and active GLP-1 at $\mathrm{t}=0-30 \mathrm{~min}$ (30 min post treatment ingestion), $\mathrm{t}=30-40 \mathrm{~min}$ (10 min post glucose injection) and $\mathrm{t}=40-150 \mathrm{~min}$ (during hyperglycemic glucose clamp) were calculated and differences between treatments tested by one-way ANOVA with Tukey posthoc analyses. Data are mean \pm SEM. Horizontal lines above AUC bars indicate statistical significance $(p \leq 0.05)$.

\subsection{Plasma Glucagon-Like Peptide 1 Response}

Total GLP-1 AUC0-30min was augmented by Gln $(p=0.05)$, but not protein $(p=0.8)$ compared with water. During the hyperglycemic glucose clamp, total GLP-1 remained significantly increased after both Gln $(p=0.02)$ and protein $(p=0.02)$ compared with water (Figure 1E,F). Active GLP-1 AUC $0-30$ min was not significantly different between treatments $(p=0.3$; Figure $1 \mathrm{G}, \mathrm{H})$. During the hyperglycemic clamp, active GLP-1 was increased after protein $(p=0.03)$ and tended to increase after $\operatorname{Gln}(p=0.08)$ compared with water (Figure 1G,H).

\section{Discussion}

We demonstrated that glutamine and whole protein low in glutamine ingested prior to intravenous hyperglycemia were similarly effective in restoring first-phase insulin response in a cohort of well-controlled type 2 diabetes patients. First- and second- phase insulin secretion are impaired in type 2 diabetes and under hyperglycemic glucose clamp conditions, endogenous GLP-1 is reported to augment both phases of insulin secretion in response to duodenal nutrition perfusion [13]. van der Klaauw and colleagues 
have recently reported that high protein mixed meals were more efficacious in enhancing GLP-1 excursions postprandially compared with isocaloric high fat or high carbohydrate mixed meals in healthy volunteers, an effect potentially attributed to glutamine [14]. No previous study however, directly compared the effect of isocaloric whole protein and L-glutamine on GLP-1 response.

We report that glutamine was more efficacious in increasing GLP-1 in the circulation 30 min post ingestion, but that both glutamine and whole protein low in glutamine restored first-phase insulin response. Other incretins were not measured in the present study and could have explained the augmented insulin response associated with the protein ingestion. In particular, gastric inhibitory polypeptide (GIP) could have been enhanced by ingestion of whole protein [15]. While previous studies suggested impaired insulinotropic effect of GIP in type 2 diabetes patients [16], a recent study proposed a certain degree of contribution of GIP to the incretin-stimulated insulin secretion observed in type 2 diabetes patients using the hyperglycemic glucose clamp together with duodenal nutrition perfusion [13]. Another potential contributor to the augmented insulin response in the whole protein treatment in the present study is whey protein $[17,18]$. The augmented second-phase insulin response observed with whole protein ingestion in the present study is consistent with the increase in intact GLP-1 in the circulation during this time.

Previously, we have reported that a similar dose of glutamine ingested with a meal increased the early active GLP-1 response, but not the early insulin response to the meal [9]. However in the present study, glutamine increased circulating GLP-1 and restored first-phase insulin response to an IV glucose challenge. Differences between these finding are likely attributed to the different stimuli, namely a mixed meal administered orally versus glucose administered IV. Furthermore, increases of approximately 1.5-fold in circulating GLP-1 concentrations in the present study were related to first-phase insulin restoration. In support, similar scale increases in circulating GLP-1 in response to OGTT were associated with restoration of first-phase insulin response to IVGTT in severely obese type 2 diabetes patients undergoing bariatric surgery [19].

The main strengths of this study are the use of the hyperglycemic glucose clamp, enabling the investigation of the treatments on first- and second- phase insulin response. Furthermore, the test treatments were energy and fat matched to negate possible effects of energy and fat on gastric emptying, insulin and incretin response. Furthermore, the randomized crossover design increased the power to detect differences in response in a relatively small cohort. The two main limitations were the lack of a healthy control group and the relatively small cohort studied.

\section{Conclusions}

Both L-glutamine and whole protein restored first-phase insulin response in type 2 diabetes patients. Larger studies are required to further investigate the utility of similar approaches in improving insulin secretory capacity in type 2 diabetes.

\section{Acknowledgments}

We thank the research nurses Lynne Schofield, Renee Richens and Vanessa Travers of the Clinical Research Facility of Garvan Institute of Medical Research, Sydney.

The study was supported by a National Health and Medical Research Council (NHMRC) of Australia Project Grant (no. 535949) and Diabetes Australia Research Trust. JRG was supported by a Neil Hamilton 
Fairley Fellowship from NHMRC and the Don Chisholm Fellowship and DS-B by the Australian Diabetes Society and Sachdev Foundation (the Garvan Research Foundation).

\section{Author Contributions}

D.S.-B., D.J.C. and J.R.G. conceived and designed research; D.S.-B., J.J.H. and J.R.G. conducted research; D.S.-B. analysed data and wrote the paper. All authors read and approved the final manuscript. D.S.-B. and J.R.G. take full responsibility for the work as a whole, including the study design, access to data, and the decision to submit and publish the manuscript.

\section{Conflicts of Interest}

The authors declare no conflict of interest. The founding sponsors had no role in the design of the study; in the collection, analyses, or interpretation of data; in the writing of the manuscript, and in the decision to publish the results.

\section{References}

1. Drucker, D.J. The biology of incretin hormones. Cell Metab. 2006, 3, 153-165.

2. Holst, J.J. The physiology of glucagon-like peptide 1. Physiol. Rev. 2007, 87, 1409-1439.

3. Calanna, S.; Christensen, M.; Holst, J.J.; Laferrere, B.; Gluud, L.L.; Vilsboll, T.; Knop, F.K. Secretion of glucagon-like peptide-1 in patients with type 2 diabetes mellitus: Systematic review and meta-analyses of clinical studies. Diabetologia 2013, 56, 965-972.

4. Salehi, M.; Prigeon, R.L.; Aulinger, B.; D’Alessio, D.A. Effect of endogenous GLP-1 on insulin secretion in type 2 diabetes. Diabetes 2010, 59, 1330-1337.

5. Reimann, F.; Williams, L.; da Silva Xavier, G.; Rutter, G.A.; Gribble, F.M. Glutamine potently stimulates glucagon-like peptide-1 secretion from glutag cells. Diabetologia 2004, 47, 1592-1601.

6. Tolhurst, G.; Zheng, Y.; Parker, H.E.; Habib, A.M.; Reimann, F.; Gribble, F.M. Glutamine triggers and potentiates glucagon-like peptide-1 secretion by raising cytosolic $\mathrm{Ca}^{2+}$ and camp. Endocrinology 2011, 152, 405-413.

7. Greenfield, J.R.; Farooqi, I.S.; Keogh, J.M.; Henning, E.; Habib, A.M.; Blackwood, A.; Reimann, F.; Holst, J.J.; Gribble, F.M. Oral glutamine increases circulating glucagon-like peptide 1, glucagon, and insulin concentrations in lean, obese, and type 2 diabetic subjects. Am. J. Clin. Nutr. 2009, 89, 106-113.

8. Chang, J.; Wu, T.; Greenfield, J.R.; Samocha-Bonet, D.; Horowitz, M.; Rayner, C.K. Effects of intraduodenal glutamine on incretin hormone and insulin release, the glycemic response to an intraduodenal glucose infusion, and antropyloroduodenal motility in health and type 2 diabetes. Diabetes Care 2013, 36, 2262-2265.

9. Samocha-Bonet, D.; Wong, O.; Synnott, E.L.; Piyaratna, N.; Douglas, A.; Gribble, F.M.; Holst, J.J.; Chisholm, D.J.; Greenfield, J.R. Glutamine reduces postprandial glycemia and augments the glucagon-like peptide-1 response in type 2 diabetes patients. J. Nutr. 2011, 141, 1233-1238.

10. Gannon, M.C.; Nuttall, F.Q. Amino acid ingestion and glucose metabolism-A review. IUBMB Life 2010, 62, 660-668. 
11. Lenders, C.M.; Liu, S.; Wilmore, D.W.; Sampson, L.; Dougherty, L.W.; Spiegelman, D.; Willett, W.C. Evaluation of a novel food composition database that includes glutamine and other amino acids derived from gene sequencing data. Eur. J. Clin. Nutr. 2009, 63, 1433-1439.

12. Lerche, S.; Soendergaard, L.; Rungby, J.; Moeller, N.; Holst, J.J.; Schmitz, O.E.; Brock, B. No increased risk of hypoglycaemic episodes during $48 \mathrm{~h}$ of subcutaneous glucagon-like-peptide-1 administration in fasting healthy subjects. Clin. Endocrinol. 2009, 71, 500-506.

13. Woerle, H.J.; Carneiro, L.; Derani, A.; Göke, B.; Schirra, J. The role of endogenous incretin secretion as amplifier of glucose-stimulated insulin secretion in healthy subjects and patients with type 2 diabetes. Diabetes 2012, 61, 2349-2358.

14. van der Klaauw, A.A.; Keogh, J.M.; Henning, E.; Trowse, V.M.; Dhillo, W.S.; Ghatei, M.A.; Farooqi, I.S. High protein intake stimulates postprandial GLP1 and PYY release. Obesity 2013, 21, $1602-1607$.

15. Wikarek, T.; Chudek, J.; Owczarek, A.; Olszanecka-Glinianowicz, M. Effect of dietary macronutrients on postprandial incretin hormone release and satiety in obese and normal-weight women. Br. J. Nutr. 2014, 111, 236-246.

16. Nauck, M.A.; Baller, B.; Meier, J.J. Gastric inhibitory polypeptide and glucagon-like peptide-1 in the pathogenesis of type 2 diabetes. Diabetes 2004, 53, S190-S196.

17. Ma, J.; Stevens, J.E.; Cukier, K.; Maddox, A.F.; Wishart, J.M.; Jones, K.L.; Clifton, P.M.; Horowitz, M.; Rayner, C.K. Effects of a protein preload on gastric emptying, glycemia, and gut hormones after a carbohydrate meal in diet-controlled type 2 diabetes. Diabetes Care 2009, 32, 1600-1602.

18. Salehi, A.; Gunnerud, U.; Muhammed, S.J.; Ostman, E.; Holst, J.J.; Bjorck, I.; Rorsman, P. The insulinogenic effect of whey protein is partially mediated by a direct effect of amino acids and gip on beta-cells. Nutr. Metab. 2012, 9, 48.

19. Salinari, S.; Bertuzzi, A.; Asnaghi, S.; Guidone, C.; Manco, M.; Mingrone, G. First-phase insulin secretion restoration and differential response to glucose load depending on the route of administration in type 2 diabetic subjects after bariatric surgery. Diabetes Care 2009, 32, 375-380.

(C) 2015 by the authors; licensee MDPI, Basel, Switzerland. This article is an open access article distributed under the terms and conditions of the Creative Commons Attribution license (http://creativecommons.org/licenses/by/4.0/). 